\begin{tabular}{|c|c|c|}
\hline & $\begin{array}{c}\text { JURNAL } \\
\text { PENELITIAN PENDIDIKAN IPA }\end{array}$ & $\begin{array}{l}\text { e-ISSN : } 2407-795 X \\
\text { p-ISSN : 2460-2582 }\end{array}$ \\
\hline WIPIPA & http://jppipa.unram.ac.id/index.php/jppipa & $\begin{array}{l}\text { Vol 2, No, } 2 \\
\text { Juli } 2016\end{array}$ \\
\hline
\end{tabular}

\title{
PENGARUH PENDEKATAN VAK (VISUALIZATION, AUDITORY, KINESTETIC) TERHADAP HASIL BELAJAR FISIKA SISWA SMPN 10 MATARAM TAHUN AJARAN 2013/2014
}

\author{
Siswadi $^{1}$, Susilawati ${ }^{2}$, Hikmawati ${ }^{2}$ \\ Alumni Pendidikan Fisika FKIP Universitas Mataram ${ }^{1}$ \\ Dosen Pendidikan Fisika FKIP Universitas Mataram ${ }^{2}$ \\ Email: susilawatihambali@yahoo.co.id
}

\begin{tabular}{ll}
\hline Key Words & Abstract \\
\cline { 2 - 3 } Approach & This research aimed to examine the effect of VAK approach (Visualization, \\
Auditory, Kinestetic) towards the result of learning physics of students at SMPN \\
10 Mataram in academic year 2013/2014. The kind of research used was \\
experimental design with design of research was randomized posttest only \\
control design. The sampling technique used was cluster random sampling. \\
Population in this research was all the students from the eight grade at SMPN 10 \\
Mataram, while the sample was 25 students of class VIII A as the experimental \\
group and 27 students of class VIII B as the control group. The data obtained \\
was analyzed by using t-test of two-tailed. t-count was 4.78 and t-table was 2.00 \\
with significance level 0.05. Hence, t-table is smaller than t-count or t-count is \\
bigger than t-table. It means that Null Hypothesis was rejected and Alternate \\
Hypothesis was accepted. It means that the application of VAK Approach \\
(Visualization, Auditory, Kinestetic) affects the results of learning physics of \\
students.
\end{tabular}

\begin{tabular}{ll}
\hline Kata Kunci & Abstrak \\
\cline { 1 - 3 } Pendekatan & Penelitian ini bertujuan untuk mengetahui pengaruh pendekatan VAK \\
VAK & (Visualization, Auditory, Kinestetic) terhadap hasil belajar fisika siswa SMP \\
& Negeri 10 Mataram tahun ajaran 2013/2014. Jenis penelitian yang digunakan \\
adalah penelitian eksperimen dengan bentuk desain penelitian yaitu randomized \\
posttest only control design. Teknik pengambilan sampel menggunakan cluster \\
random sampling. Populasi dalam penelitian ini adalah semua kelas VIII SMPN \\
10 Mataram sedangkan sampelnya adalah siswa kelas VIII A berjumlah 25 \\
siswa sebagai kelas eksperimen dan kelas VIII B berjumlah 27 siswa sebagai \\
kelas kontrol. Data hasil belajar dianalisis menggunakan uji-t dua pihak dan \\
diperoleh thitung sebesar 4.78 dan ttabel sebesar 2.00 dengan taraf signifikansi \\
O.05 sehingga ttabel lebih kecil dari thitung atau thitung lebih besar dari ttabel \\
artinya hipotesis Ho ditolak dan Ha diterima. Hal ini berarti pendekatan VAK \\
(Visualization, Auditory, Kinestetic) berpengaruh terhadap hasil belajar fisika \\
siswa SMP Negeri 10 Mataram tahun ajaran 2013/2014.
\end{tabular}




\section{PENDAHULUAN}

Ilmu Pengetahuan Alam (IPA) berkaitan dengan cara mencari tahu tentang alam secara sistematis, sehingga IPA bukan hanya penguasaan kumpulan pengetahuan yang berupa fakta-fakta, konsep-konsep atau prinsip-prinsip saja tetapi juga merupakan suatu proses penemuan. Pendidikan IPA diharapkan dapat menjadi wahana bagi peserta didik untuk mempelajari diri sendiri dan alam sekitar, serta prospek pengembangan lebih lanjut dalam penerapannya dalam kehidupan sehari-hari, termasuk dalam pelajaran fisika (Siswadi, 2014).

Pembelajaran fisika memiliki peranan yang sangat penting untuk meningkatkan kualitas suatu bangsa. Pembelajaran fisika diarahkan ke suatu tujuan yaitu agar siswa dapat mengembangkan kemampuan intelektualnya, berfikir kritis, logis, dan ilmiah serta mampu memahami konsep, dan memecahkan masalah terutama yang berkaitan dengan kehidupan sehari-hari. Untuk mencapai tujuan tersebut, guru harus terampil dalam memilih dan menggunakan model atau pendekatan pembelajaran yang tepat, tidak hanya pendekatan konvensional saja. Model atau pendekatan pembelajaran yang digunakan guru diharapkan dapat mengarahkan siswa untuk aktif dan kreatif, sehingga pembelajaran menjadi terpusat pada siswa. Pembelajaran fisika dikatakan berhasil apabila siswa telah menguasai materi fisika secara kognitif, psikomotor, dan afektif (Siswadi, 2014).

Dari hasil observasi melalui wawancara bersama guru mata pelajaran sains fisika kelas VIII SMPN 10 Mataram, peneliti mendapati bahwa data awal hasil belajar IPA fisika siswa kelas VIII tergolong rendah dan dibawah standar ketuntasan belajar yang ditetapkan, yaitu 70. Rendahnya nilai fisika tersebut membuktikan bahwa kegiatan pembelajaran belum dilakukan secara optimal dan masalah yang terdapat adalah kurang aktifnya siswa di kelas. Kekurangaktifan siswa di kelas ini disebabkan karena pembelajaran fisika cenderung disajikan secara abstrak dan masih terpusat pada guru sehingga siswa menjadi pasif. Guru lebih banyak menyampaikan materi fisika melalui metode ceramah. Materi fisika yang cukup banyak dan harus disampaikan dalam waktu singkat. Penyampaian materi fisika dengan pendekatan konvensional melalui metode ceramah ini mengakibatkan prestasi siswa cenderung menjadi rendah. Selain itu, pengunaan media pembelajaran sebagai alat penunjang pembelajaran belum dilaksanakan dengan maksimal. Ini disebabkan karena beberapa media 
pembelajaran seperti media audio-visual seperti LCD proyektor, komputer dan media audio visual lainnya yang masih belum memadai dan cukup di sekolah. Hal ini mengakibatkan hasil belajar siswa cenderung masih rendah (Siswadi, 2014).

Berdasarkan uraian tersebut, maka diperlukan sebuah alternatif pembelajaran yang mengaktifkan siswa dalam kegiatan pembelajaran. Untuk mengarahkan siswa agar dapat menjadi aktif dan mampu meningkatkan prestasinya, maka diperlukan suatu metode atau pendekatan pembelajaran yang bervariasi. Salah satu pendekatan pembelajaran yang dapat digunakan adalah VAK yang merupakan pendekatan pembelajaran yang memaksimalkan penggabungan semua indera siswa dalam proses pembelajaran,baik penglihatan, gerakan fisik maupun aktivitas intelektual siswa (Siswadi, 2014).

Pendekatan VAK diciptakan oleh Grinder, dkk (1981) ilmuan yang memiliki banyak pengalaman tentang bagaimana agar pembelajaran itu tidak membosankan dengan memaksimalkan potensi seluruh indera siswa. Pendekatan VAK terdiri atas 3 unsur yakni: Visualization, Auditori dan Kinestetik. Visualization maksudnya adalah belajar dengan mengamati, melihat, dan memperhatikan. Auditori maksudnya adalah belajar dengan mendengarkan, menyimak, berbicara, presentasi, argumentasi, mengemukakan pendapat, dan menanggapi. Kinestetik maksudnya belajar dengan indera peraba, praktis melibatkan fisik dan menggunakan serta menggerakkan tubuh sewaktu belajar. Ketiga cara belajar ini harus ada agar belajar berlangsung optimal. Karena ini semuanya terpadu, yakni belajar yang paling baik bisa berlangsung jika semuanya simultan. Seperti yang diungkapkan oleh Vernon (1983) dalam DePorter (2009), "kita belajar $10 \%$ dari apa yang kita baca, 20\% dari apa yang kita dengar, 30\% dari apa yang kita lihat, 50\% dari apa yang kita lihat dan dengar, 70\% dari apa yang kita katakan, dan $90 \%$ dari apa yang kita lakukan". Sehingga belajar akan lebih efektif jika siswa melibatkan seluruh indera yang mereka miliki” (DePorter, 2009).

Pendekatan VAK (Visualization, Auditory, Kinestetic) merupakan pendekatan pembelajaran yang dapat mengeksplorasi potensi dalam diri siswa dan mengoptimalkannya dengan memaksimalkan seluruh indranya dan memaksimalkan gaya belajar yang dimiliki oleh masing-masing siswa baik Visualization, Auditory, maupun Kinestetic dalam kegiatan pembelajaran. Pendekatan VAK adalah pendekatan pembelajaran yang terdiri atas 3 unsur yaitu: Visualization maksudnya adalah 
belajar lebih mudah dengan cara melihat, mengamati atau membaca, Auditory maksudnya adalah belajar lebih mudah dengan cara berbicara dan mendengar sedangkan Kinestetic maksudnya adalah belajar lebih mudah dengan cara aktivitas bergerak dan berbuat (Prijosaksono dan Marlan, 2001). Ketiga cara belajar ini harus ada agar belajar berlangsung optimal. Karena ini semuanya terpadu, yakni belajar yang paling baik bisa berlangsung jika semuanya simultan.

Dalam Rose (2002), pendekatan VAK dijelaskan sebagai strategi VAK yang memiliki ketiga komponen seperti yang dijelaskan di atas yaitu : Visual yang memiliki arti belajar melalui melihat sesuatu seperti gambar atau diagram, pertunjukan, peragaan, atau menyaksikan video. Auditori yang memiliki arti belajar melalui mendengar sesuatu seperti mendengarkan kaset audio, ceramah-kuliah, diskusi, debat, dan instruksi (perintah verbal). Kinestetik yang memiliki arti belajar melalui aktivitas fisik dan keterlibatan langsung seperti bergerak, menyetuh, dan merasakan/mengalami sendiri.

Hasil belajar merupakan hasil yang dicapai setelah melakukan proses pembelajaran yang berupa perbuatan, nilai-nilai, pengertian-pengertian, sikapsikap, apresiasi dan keterampilan yang mencakup tiga aspek, yaitu aspek kognitif (pengetahuan), afektif (sikap), dan psikomotorik (keterampilan) (Siswadi, 2014).

\section{METODE PENELITIAN}

Jenis penelitian yang digunakan dalam penelitian ini adalah penelitian eksperimen. Metode penelitian eksperimen dapat diartikan sebagai metode penelitian yang digunakan untuk mencari pengaruh perlakuan tertentu terhadap yang lain dalam kondisi yang terkendalikan (Sugiyono, 2011). Eksperimen adalah suatu cara untuk mencari hubungan sebab akibat (hubungan kausal) antara dua faktor yang sengaja ditimbulkan oleh peneliti dengan mengeliminasi atau mengurangi atau menyisihkan faktor- faktor lain yang mengganggu (Arikunto, 2010). Penelitian dilaksanakan pada bulan Oktober 2013 sampai dengan September 2014 dan bertempat di SMP Negeri 10 Mataram. Desain penelitian yang digunakan dalam penelitian ini adalah Randomized Posttest Only Control Design. Desain penelitian Randomized Posttest Only Control Design bertujuan untuk memperoleh perbedaan hasil belajar fisika siswa antara kelas eksperimen dan kontrol sehingga pada akhirnya akan mendapatkan pengaruh dari pendekatan pembelajaran yang digunakan. Dalam desain penelitian ini sekelompok subjek 
diambil secara rambang menjadi dua kelompok, yaitu kelompok eksperimen dan kelompok kontrol. Kelompok pertama diberikan perlakuan, sedangkan kelompok kedua diperlakukan sebagai kelompok kontrol.

$$
\text { Populasi adalah wilayah }
$$

generalisasi yang terdiri atas: obyek/subyek yang mempunyai kualitas dan karakteristik tertentu yang ditetapkan oleh peneliti untuk dipelajari dan kemudian ditarik kesimpulannya (Sugiyono, 2013). Populasi dalam penelitian ini adalah seluruh siswa kelas VIII SMPN 10 Mataram dengan jumlah siswa 360 siswa yang terbagi atas 10 kelas. Dalam penelitian ini, cara pengambilan sampel menggunakan teknik cluster random sampling. Cluster random sampling yaitu teknik penarikan sampel yang digunakan apabila populasi atau sampel yang tersedia adalah berupa unit-unit rumpun dalam populasi (Setyosari, 2012). Adapun kelas yang menjadi sampel dalam penelitian ini adalah kelas VIII A sebanyak 25 siswa sebagai kelas eksperiment dan kelas VIII B sebanyak 27 siswa sebagai kelas kontrol yang diperoleh peneliti dari pengambilan sampel secara random/acak seperti yang dijelaskan diatas.

Pada penelitian ini ada tiga variabel yang menjadi fokus penelitian yaitu variabel bebas, variavel terikat dan variabel kontrol. Variabel bebas pada penelitian ini adalah pendekatan VAK. Variabel terikat adalah hasil belajar fisika siswa kelas VIII SMPN 10 Mataram tahun ajaran 2013/2014 pada ranah kognitif, afektif, dan psikomotor. Variabel kontrol berupa kemampuan awal siswa pada kelas eksperimen dan kelas kontrol dianggap sama, guru, materi, tujuan pembelajaran, instrumen yang digunakan, dan cara penilaian. Teknik pengumpulan data pada penelitian ini adalah tes hasil belajar.

Data hasil belajar merupakan data hasil tes akhir yang dilakukan setelah perlakuan. Data tes akhir diperoleh dengan menggunakan instrumen yang telah diuji validitasnya dan reliabilitas. Analisis validitas instrumen menggunakan rumus product moment untuk uji validitas soal dan Rumus Sperman Brown untuk uji reliabilitas soal (Arikunto, 2009). Analisis data tes akhir menggunakan uji-t dua pihak.

\section{HASIL DAN PEMBAHASAN}

Hasil penelitian berupa hasil uji instrumen dan hasil uji-t tes awal dan tes akhir. Validitas butir soal yang dianalisis dengan rumus product moment yang dikonsultasikan dengan tabel $r$ product moment pada taraf kepercayaan 95\%. Reliabitilas instrument pada taraf 
kepercayaan $95 \%$ diperoleh $\mathrm{r}_{\text {hitung }}$ sebesar 0,883 .

Tabel 1. Data Hasil Tes Akhir

\begin{tabular}{|l|l|l|l|l|}
\hline Kelas & Rata-Rata & Varians & thitung $^{\text {t tabel }}$ \\
\hline Eksperimen & 76.48 & 105.76 & & \\
\cline { 1 - 3 } Kontrol & 66.67 & 77.54 & 4.7795 & 2.000 \\
& & & & \\
\hline
\end{tabular}

Data tes akhir homogen berdasarkan uji-F dan normal berdasarkan uji chi kuadrat. Berdasarkan hasil analisis uji-t dua pihak dengan taraf signifikan 5\%, diperoleh thitung sebesar 4.7795. Nilai thitung ini kemudian dibandingkan dengan nilai ttabel dengan $\mathrm{db}=50$. Nilai ttabel yang diperoleh pada taraf signifikan 5\% dan uji dua pihak adalah sebesar 2.000. Oleh karena nilai $t_{\text {hitung }}$ (4.7795) lebih besar dibandingkan nilai tabel (2.000) maka $\mathrm{H}_{\mathrm{o}}$ ditolak dan $\mathrm{H}_{\mathrm{a}}$ diterima. Hal ini menunjukkan bahwa terdapat pengaruh pendekatan VAK (Visualization, Auditory, kinesthetic) terhadap hasil belajar fisika siswa SMP Negeri 10 Mataram tahun ajaran 2013/2014.

Hasil belajar afektif yang diteliti dalam penelitian ini meliputi tingkat penerimaan (receiving), pemberian respon (responding), penentuan sikap (valuing), organisasi, dan pembentukan pola hidup. Tingkat penerimaan (receiving) yang dimaksud ialah mengikuti kegiatan pembelajaran dengan disiplin. Tingkat pemberian respon (responding) yaitu aktif dalam kegiatan pembelajaran. Tingkat penentuan sikap (valuing) yaitu menunjukkan respon dan sikap positif pada saat kegiatan pembelajaran serta mampu menghargai orang lain. Tingkat organisasi meliputi partisipasi siswa dalam kegiatan pembelajaran atau melakukan percobaan, sedangkan untuk tingkat pembentukan pola hidup yakni siswa dapat memiliki rasa tanggung jawab terhadap tugas yang diberikan.

Persentase rata-rata hasil belajar afektif pada kelas eksperimen dari pertemuan pertama hingga pertemuan ketiga ialah $79.40 \%, 81.80 \%, 85.80 \%$ dan termasuk kategori baik, sangat baik, dan sangat baik. Hal ini menunjukkan bahwa hasil belajar pada ranah afektif mengalami peningkatan pada setiap pertemuan. Sedangkan persentase ratarata hasil belajar afektif pada kelas kontrol dari pertemuan pertama hingga pertemuan ketiga ialah $72.96 \%, 78.89 \%$, $82.04 \%$ dan termasuk kategori cukup, baik dan baik. Hal ini menunjukkan bahwa hasil belajar pada ranah afektif mengalami peningkatan pada setiap pertemuan.

Hasil belajar ranah psikomotor yang diteliti dalam penelitian ini meliputi jenjang menirukan, memanipulasi, pengalamiahan, dan artikulasi yang dijabarkan dalam kegiatan memilih alat dan bahan praktikum sesuai dengan yang 
tertera pada lembar kerja siswa (LKS), merancang serta melakukan percobaan sesuai dengan langkah kerja yang tertera pada lembar kerja siswa (LKS), mampu dalam mengukur serta mengamati pada saat kegiatan praktikum serta memperoleh data yang tepat, dan mampu mengkomunikasikan hasil percobaan dengan baik dalam bentuk presentasi. Besarnya rata-rata persentase nilai pada setiap pertemuan dari pertemuan pertama hingga pertemuan ketiga, yakni $57.50 \%$, $62.25 \%, 79.75 \%$.

Peningkatan yang lebih besar terjadi pada kelas eksperimen yang diberikan perlakuan menggunakan pendekatan VAK dibandingkan kelas kontrol yang diberi perlakuan dengan metode ceramah. Hal ini terjadi karena pada kelas eksperimen, siswa didorong untuk memaksimalkan kemampuan visual, auditory dan kinestetic yang mereka miliki. Belajar secara visual dilakukan dengan bantuan slide presentasi dan video, belajar secara auditory dilakukan dengan disukusi dan tanya jawab bersama guru dan teman sedangkan belajar secara kinestetik dilakukan melalui praktikum.

Penelitian pendekatan VAK ini sudah banyak diteliti sebelumnya yakni yang dilakukan oleh Arifin (2008), Purba (2012) dan Purnawati (2013), mendapatkan hasil dan kesimpulan bahwa penelitian mereka menunjukkan terdapat pengaruh yang signifikan terhadap hasil belajar dan prestasi belajar siswa. Hasil penelitian Ahmad (2015), menemukan bahwa pendekatan VAK lebih efektif dalam meningkatkan kemampuan penalaran IPA daripada pendekatan konvensional pada kelompok siswa yang memiliki belief tinggi tentang IPA, karena pendekatan VAK menuntut siswa untuk lebih aktif dan berpikir kritis dalam kegiatan pembelajaran. Jadi tampak dari hasil penelitian yang didapatkan dan analisis statistik yang digunakan maka dapat dibuktikan dan peneliti berkesimpulan bahwa pendekatan VAK (Visualization, Auditory, Kinestetik) berpengaruh terhadap hasil belajar fisika siswa SMPN 10 Mataram tahun ajaran 2013/2014, dimana pengaruh tersebut adalah positif karena adanya peningkatan hasil belajar yang dapat dilihat dari peningkatan nilai siswa yang didapatkan.

\section{KESIMPULAN DAN SARAN}

Berdasarkan rumusan masalah, hasil penelitian, dan pembahasan maka dapat disimpulkan bahwa terdapat pengaruh pendekatan VAK (Visualization, Auditory, Kinestetik) terhadap hasil belajar fisika siswa SMPN 10 Mataram tahun ajaran 2013/2014. 


\begin{abstract}
Bagi siswa, pada saat pelakasanaan pembelajaran dengan menggunakan pendekatan VAK (Visualization, Auditory, Kinestetik), sebaiknya lebih serius dan fokus dalam mengikuti kegiatan pembelajaran agar hasil yang diperoleh lebih optimal serta memperhatikan penjelasan yang disampaikan oleh guru. Bagi guru fisika, pendekatan VAK (Visualization, Auditory, Kinestetik) dapat digunakan sebagai alternatif proses belajar mengajar di kelas. Bagi peneliti lain yang ingin meneliti pendekatan VAK (Visualization, Auditory, Kinestetik) diharapkan dapat menerapkannya pada materi yang lain serta dapat divariasikan dengan media lainnya.
\end{abstract}

\section{DAFTAR PUSTAKA}

Ahmad, Nurul Qomariyah. 2015. Pengaruh Pendekatan Pembelajaran Dan Belief Tentang IPA Terhadap Kemampuan Penalaran IPA. Jurnal Pencerahan, Volume 9, Nomor 1, (Maret) 2015.

Arikunto, S. 2009. Dasar-dasar Evaluasi Pendidikan. Jakarta: PT Bumi Aksara.

Arikunto, S. 2010. Prosedur Penelitian (Revisi 2010). Jakarta: PT Rineka Cipta.

DePorter, B. 2009. Quantum Teaching, Mempraktikkan Quantum Learning di Ruang-Ruang Kelas. Bandung: Kaifa.
Prijosaksono, A dan Marlan, M. 2001. Self Managemen. Jakarta: Gramedia.

Rose, C dan Nicholl, J Malcolm. 2002. Accelerrated Learning For 21st Century. Bandung: Nuansa.

Setyosari, P. 2012. Metodologi Penelitian Pendidikan dan Pengembangan. Jakarta: Kencana.

Siswadi. 2014. Pengaruh Pendekatan VAK (Visualization, Auditory, Kinestetic) terhadap Hasil Belajar Fisika Siswa SMPN 10 Mataram tahun Ajaran 2013/2014. Skripsi. Tidak Dipublikasikan. Universitas Mataram: Mataram.

Sugiyono. 2011. Metode Penelitian
Administrasi.
Alfabeta.

Sugiyono. 2013. Statistika untuk Penelitian. Bandung: Alfabeta. 